\title{
Expression of Homeobox A9 (HOXA9) in Non- Melanoma Skin Cancer: A Clinical and Immunohistochemical study
}

\author{
Wafaa Ahmed Shehata ${ }^{1}$, Mohamed A. Shoeib ${ }^{1}$, Shimaa Kamel Salama*1, Aiat Shaban Hemida ${ }^{2}$ \\ Departments of ${ }^{1}$ Dermatology, Andrology and STDs and ${ }^{2}$ Pathology, Faculty of Medicine, Menoufia University, Egypt \\ *Corresponding author: Shimaa Kamel Salama, Mobile: (+20)1061068186, E-mail: shimaakamel2018@gmail.com
}

\begin{abstract}
Background: Homeobox A9 (HOXA9) has been implicated in acute myeloid leukemia and cancer breast but, little is known about HOXA9 expression in non- melanoma skin cancer (NMSC); basal cell carcinoma (BCC) and cutaneous squamous cell carcinoma (cSCC). Objective: The aim of the current work was to study HOXA9 expression in NMSC by immunohistochemical method. Patients and Methods: This case-control study included a total of 45 cases with NMSC; 15 BCC and 30 SCC beside 45 age and sex-matched normal apparently healthy controls, selected from Dermatology, Andrology \& Sexually transmitted diseases (STDs) Outpatient Clinic, Menoufia University Hospital, during the period December 2018 to June 2020. Clinical evaluation and histopathological evaluation confirmed the diagnosis of SCC and BCC. Results: Expression of HOXA9 in the overlying epidermis was positive in $83.3 \%$ of SCC cases with strong intensity in $68 \%$ and nucleocytoplasmic localization in $100 \%$. HOXA9 was positive in $60 \%$ of $\mathrm{BCC}$ cases with mild intensity in $77.8 \%$ and nucleocytoplasmic localization in $100 \%$. In control sections, HOXA9 was in all sections (100\%) with strong intensity in $77.8 \%$, and nucleocytoplasmic localization in all of them $100 \%$. Regarding tumor islands; expression of HOXA9 was positive in $26(86.7 \%)$ cases of SCC and was positive in $2(13.3 \%)$ of BCC cases. There was significant higher HOXA9 H- score in control skin than NMSC $(\mathrm{p}<0.001)$. Conclusions: It could be concluded that HOXA9 may be implicated in pathogenesis and may represent a target therapy for NMSC.
\end{abstract}

Keywords: Basal cell carcinoma, Squamous cell carcinoma, Homeobox A9.

\section{INTRODUCTION}

Non melanoma skin cancer (NMSC) is considered the most common type of cancer in Caucasians, with proceeding increment in incidence worldwide $^{(\mathbf{1})}$. In fact; NMSC is the most common type with a relative incidence increasing rate up to $10 \%$ per annum, with 2-3 million new cases each year universally ${ }^{(2)}$.

As a whole, NMSCs are chiefly represented by basal cell carcinoma (BCC) and squamous cell carcinoma (SCC). BCC accounts for $75 \%$ of cases of NMSC and SCC accounts for the remaining larger part cases with NMSC. While metastasis from BCC is extremely rare, metastasis from high-risk SCC may be fatal (3). NMSC arises from epidermal cells and its etiopathogenesis is multifactorial, nevertheless; exposure of skin to physical carcinogenic agents is considered the most established risk factor. Certainly, ultraviolet radiation (UVR) has an important role to drive the malignant transformation of progenitor cells (4). Additional risk factors for the development of BCC and SCC include concomitant diseases and dedicated treatments (i.e., psoriasis), chronic exposure to human papilloma virus, immunosuppressive drugs used in transplanted patients and targeted therapies for the treatment of other cancers ${ }^{(5)}$.

The information of the essential occasions driving NMSC has given the basis for the improvement of new helpful procedures that incorporate both target ed agents and immunotherapy ${ }^{(1)}$.

The homeobox, a 60-amino acid-encoding DNA arrangement, at first found within the genome of the natural product fly Drosophila, was hence distinguished all through the three kingdoms of multicellular living beings. Homeobox-containing genes encode DNA-binding proteins that direct quality expression and control different perspectives of morphogenesis and cell separation ${ }^{(6)}$. In mammals; the HOX genes, are arranged into four clusters (A, B, C and D) on separate chromosomes ${ }^{(7)}$. Homeobox A (HOXA) cluster genes are members of the HOX family, accomplish a significant role in normal development of organs. It has been stated that expression of HOXA gene in various types of cancer is associated with poor patient prognosis. Though, the role of HOXA genes, as well as their expression, in NMSC remains unidentified ${ }^{(\mathbf{8})}$.

Therefore, the present work was aimed to investigate HOXA9 expression in patients with NMSC and to correlate the results with available clinicopathological data.

\section{PATIENTS AND METHODS}

This case-control study included a total of 45 cases with NMSC; 15 BCC and 30 SCC beside 45 age and sex-matched normal apparently healthy controls, selected from Dermatology, Andrology \& Sexually transmitted diseases (STDs) Outpatient Clinic, Menoufia University Hospital. This study was conducted between December 2018 to June 2020. Clinical evaluation and histopathological evaluation confirmed the diagnosis of SCC and BCC. 


\section{Ethical approval:}

All participants signed a written informed consent and the study was approved by the Local Ethical Research Committee of Menoufia University Hospital, also it was in accordance with Declaration of Helsinki 1975 (revised in 2000).

Exclusion criteria: cases with associated infections, inflammatory conditions, and any other dermatological diseases.

Collection of data from every patient was done with emphasis on age, sex, site of the lesion, duration of disease and family history of similar conditions. Additionally, thorough general and detailed dermatological examinations were conducted.

\section{Skin Biopsies:}

A punch skin biopsy was taken from every participants preceded by injection of local anesthesia at the site of biopsy; $3 \mathrm{~mm}$ punch skin biopsies were taken from the lesion and a biopsy from matched skin site of control participants was also taken. Fixation of biopsy was done using neutral formalin $10 \%$ and routine processing of tissue was conducted until formation of paraffin-embedded blocks the two sections $(4 \mu \mathrm{m}$ thick) were cut; one section for histopathological evaluation using hematoxylin and eosin stain and the other for immunostaining using HOXA9 as a primary antibody for immunostaining.

For SCC cases, classification according to degree of differentiation by the Broders system; which revealed differentiation with keratin pearl formation of $>75 \%, 50 \%-75 \%, 25 \%-50 \%$, and $<25 \%$ for grades I, II, III, and IV respectively. Then grading system divided tumors to three groups; well (Broders I), moderately, (Broders II and III), and poorly (Broders IV) differentiated tumors ${ }^{(9)}$.

\section{Immunohistochemical Staining:}

Streptavidin-biotin-amplified system was the method used for staining (10). The investigated primary antibody used was an IgG anti- HOXA9 rabbit's polyclonal antibody $(0.1 \mathrm{~mL}$ concentrated and diluted 1:150) (Chongqing Biospes Co., Ltd, catalog\# YPA2228) (7F, Bldg B, High-tech Venture Park, \# 107 Erlang Chuangye Rd, Jiulongpo District, Chongqing, 400039 China, www. Biospes.com). Sections $(5 \mu \mathrm{m})$ were mounted on positive slides (Sigma Aldrich, Poole, UK). The slides were deparaffinized and then rehydrated. The sections were treated with $10 \mathrm{mM}$ citrate buffer, $\mathrm{pH} 6.0$, at 961C for 10 to 20 minutes, followed by $10 \mathrm{~mL}$ of Tris-EDTA for 10 to 20 minutes. Blocking of endogenous peroxidase was done with peroxidaseblocking reagent (cat. \#TP-015-HD) (Lab Vision Cooperation, Fremont, CA), to prevent nonspecific background staining. HOXA9 antibody was incubated for 10 hours, then secondary antibody (Ultravision detection framework anti-polyvalent HRP/DAB, ready-to-use, Neomarker) was added. Chromogen diaminobenzidine (DAB) (Thermo Fischer scientific catalog number 36,000 Pierce Peroxidase IHC Detection Kit; Thermo Fisher Scientific, 168 Third Avenue, Waltham, MA, USA 02451) was used. Counterstaining with Mayer's hematoxylin (cat. No. 94583; Bio Genex) was followed. Prostatic cancer tissue was utilized as a positive control. Negative control using nonimmune serum was used instead of applying the primary antibody.

\section{Interpretation of immunostaining results:}

After coding the slides of all cases, they were examined and scored. Positive expression was given when apparent membranous and/or cytoplasmic and/or nuclear staining was found (11). Semiquantitative scoring system was applied. The percentage of the positive HOXA9 cells was assessed at 100× magnification field. The intensity of staining was either mild, moderate, or strong. The following formula was used to calculate Histo-Score (H-score): $\mathrm{H}$ - score $=1 \times \%$ of mildly stained cells $+2 \times \%$ of moderately stained cells $+3 \times \%$ of strongly stained cells. The score ranges between 0 and $300^{(\mathbf{1 2})}$. Then, expression in stroma was assessed similarly.

\section{Statistical Analysis}

Analysis of collected data was done using a personal computer with the Statistical Package for Social Science (SPSS) version 22 program (SPSS Inc., Chicago, USA). Qualitative data were expressed in numbers and percentages. Descriptive statistics including arithmetic mean $(\chi 2)$, standard deviation (SD), and percentage (\%) that were used to for displaying quantitative data. Chi-square test $(\chi 2$ - test) and Fisher's exacts test were used for comparison of qualitative variables, Mann Whitney $U$ test (U test) was used for quantitative variables and Kruskal-Wallis test was the test used for comparison between three or more quantitative variables. $\mathrm{P} \leq 0.05$ was considered statistically significant ${ }^{(\mathbf{1 3})}$.

\section{RESULTS}

Cases were $23(51.1 \%)$ males and $22(48.9 \%)$ females with a M: F ratio of 1:1. Their ages ranged from 25 to 80 years with $57.17 \pm 13.9$ years as $X \pm S D$ value. Control subjects were 26 (57.8\%) males and $19(42.2 \%)$ females with a M: F ratio 5:4. Their ages ranged from 22 to 75 years with $55.44 \pm 11.79$ years as a $\mathrm{X} \pm \mathrm{SD}$ value. There were no significant differences between cases and controls regarding age and sex. 
Table (1): Clinical and histopathological data of the studied cases.

\begin{tabular}{|c|c|c|c|c|}
\hline \multirow[t]{2}{*}{ Variables } & \multicolumn{2}{|c|}{ Studied $S C C$ cases $(N=30)$} & \multicolumn{2}{|c|}{ Studied BCC cases $(\mathrm{N}=15)$} \\
\hline & $\mathbf{N}$ & $\%$ & $\mathbf{N}$ & $\%$ \\
\hline \multicolumn{5}{|l|}{ Clinical data } \\
\hline $\begin{array}{ll}\text { Presentation: } & \text { Mass } \\
& \text { Ulcer }\end{array}$ & $\begin{array}{l}12 \\
18\end{array}$ & $\begin{array}{l}40 \\
60\end{array}$ & $\begin{array}{c}10 \\
5\end{array}$ & $\begin{array}{l}66.7 \\
33.3\end{array}$ \\
\hline $\begin{array}{l}\text { Site } \\
\text { Face } \\
\text { Extremities } \\
\text { Scalp } \\
\text { Vulva }\end{array}$ & $\begin{array}{c}13 \\
8 \\
4 \\
5\end{array}$ & $\begin{array}{l}43.4 \\
26.7 \\
13.3 \\
16.7\end{array}$ & $\begin{array}{l}14 \\
1 \\
0 \\
0\end{array}$ & $\begin{array}{c}93.3 \\
6.7 \\
0 \\
0\end{array}$ \\
\hline $\begin{array}{l}\text { Predisposing factors } \\
\text { Sun exposure } \\
\text { Chronic ulcer } \\
\text { Radiation therapy }\end{array}$ & $\begin{array}{c}17 \\
8 \\
5\end{array}$ & $\begin{array}{l}56.7 \\
26.7 \\
16.7\end{array}$ & $\begin{array}{c}14 \\
1 \\
0\end{array}$ & $\begin{array}{c}93.3 \\
6.7 \\
0\end{array}$ \\
\hline Family history: $\begin{array}{l}\text { Positive } \\
\text { Negative }\end{array}$ & $\begin{array}{c}0 \\
30\end{array}$ & $\begin{array}{c}0 \\
100\end{array}$ & $\begin{array}{c}0 \\
15\end{array}$ & $\begin{array}{c}0 \\
100\end{array}$ \\
\hline $\begin{array}{r}\text { Associated skin disease: } \begin{array}{r}\text { Presence } \\
\text { Absence }\end{array} \\
\end{array}$ & $\begin{array}{c}0 \\
30 \\
\end{array}$ & $\begin{array}{c}0 \\
100\end{array}$ & $\begin{array}{c}0 \\
15 \\
\end{array}$ & $\begin{array}{c}0 \\
100 \\
\end{array}$ \\
\hline $\begin{array}{l}\text { Duration in years } \\
\text { Range } \\
\text { Median } \\
X \pm S D\end{array}$ & \multicolumn{2}{|c|}{$\begin{array}{c}1-13 \\
2 \\
3.07 \pm 3.01\end{array}$} & \multicolumn{2}{|c|}{$\begin{array}{c}1-2 \\
2 \\
1.23 \pm 0.320\end{array}$} \\
\hline $\begin{array}{l}\text { Size in cm } \\
\text { Range } \\
\text { Median } \\
X \pm S D\end{array}$ & \multicolumn{2}{|c|}{$\begin{array}{c}1-25 \\
5.50 \\
7.42 \pm 6.86 \\
\end{array}$} & \multicolumn{2}{|c|}{$\begin{array}{c}2-6 \\
1.90 \\
2.43 \pm 1.30\end{array}$} \\
\hline \multicolumn{5}{|l|}{ Pathological data } \\
\hline $\begin{array}{ll}\text { Biopsy: } & \text { Incision } \\
& \text { Excision }\end{array}$ & $\begin{array}{c}4 \\
26\end{array}$ & $\begin{array}{l}13.3 \\
86.7\end{array}$ & $\begin{array}{c}4 \\
11\end{array}$ & $\begin{array}{l}26.7 \\
73.3\end{array}$ \\
\hline $\begin{array}{l}\text { Margin in excisional biopsy } \\
\text { Free } \\
\text { Involved }\end{array}$ & $\begin{array}{c}25 \\
1\end{array}$ & $\begin{array}{c}96.2 \\
3.8\end{array}$ & $\begin{array}{c}10 \\
1\end{array}$ & $\begin{array}{c}90.9 \\
9.1\end{array}$ \\
\hline $\begin{array}{l}\text { Histopathological grade of SCC } \\
\text { Well differentiated } \\
\text { Moderate differentiated } \\
\text { Poorly differentiated }\end{array}$ & $\begin{array}{c}12 \\
12 \\
6\end{array}$ & $\begin{array}{l}40 \\
40 \\
20\end{array}$ & & \\
\hline $\begin{array}{l}\text { Variant of BCC } \\
\text { Pigmented } \\
\text { Keratotic } \\
\text { Adenoid } \\
\text { Solid } \\
\text { Mixed } \\
\text { Superficial spreading }\end{array}$ & $\begin{array}{l}4 \\
2 \\
5 \\
2 \\
1 \\
1\end{array}$ & $\begin{array}{c}26.7 \\
13.3 \\
33.3 \\
13.3 \\
6.7 \\
6.7\end{array}$ & & \\
\hline
\end{tabular}

$\mathrm{N}$ : number X: Mean SD: standard deviation \%: percentage $\mathrm{cm}$ : centimeters

\section{HOXA9 Immunohistochemical Expression in the Studied Groups:}

Regarding the overlying epidermis; expression of HOXA9 was positive in $25(83.3 \%)$ cases of SCC with strong intensity in $68 \%$ and nucleocytoplasmic localization in $100 \%$ HOXA9 was positive in $9(60 \%)$ of BCC cases with mild intensity in $77.8 \%$ and nucleocytoplasmic localization in $100 \%$, while in control sections; HOXA9 was in all sections (100\%) with strong intensity in $77.8 \%$, all layers distribution and nucleocytoplasmic localization in all of them $100 \%$.

Regarding tumor islands; expression of HOXA9 was positive in $26(86.7 \%)$ cases of SCC with mild intensity in 50\% and nucleocytoplasmic localization in 92.3\% (Figure 1A).

HOXA9 was positive in 2 (13.3\%) of BCC cases with mild intensity and patchy pattern, nucleocytoplasmic localization in 100\% (Figure 1B), while in control sections; HOXA9 was in all sections $(100 \%)$ with strong intensity in $77.8 \%$, diffuse distribution in $84.4 \%$ and nucleocytoplasmic localization in all of them 100\% (Figure 1C).

HOXA9 was positive in blood vessels, skin adnexa (Figure 1D) and inflammatory cells of all the 
studied groups with no significant difference between them.

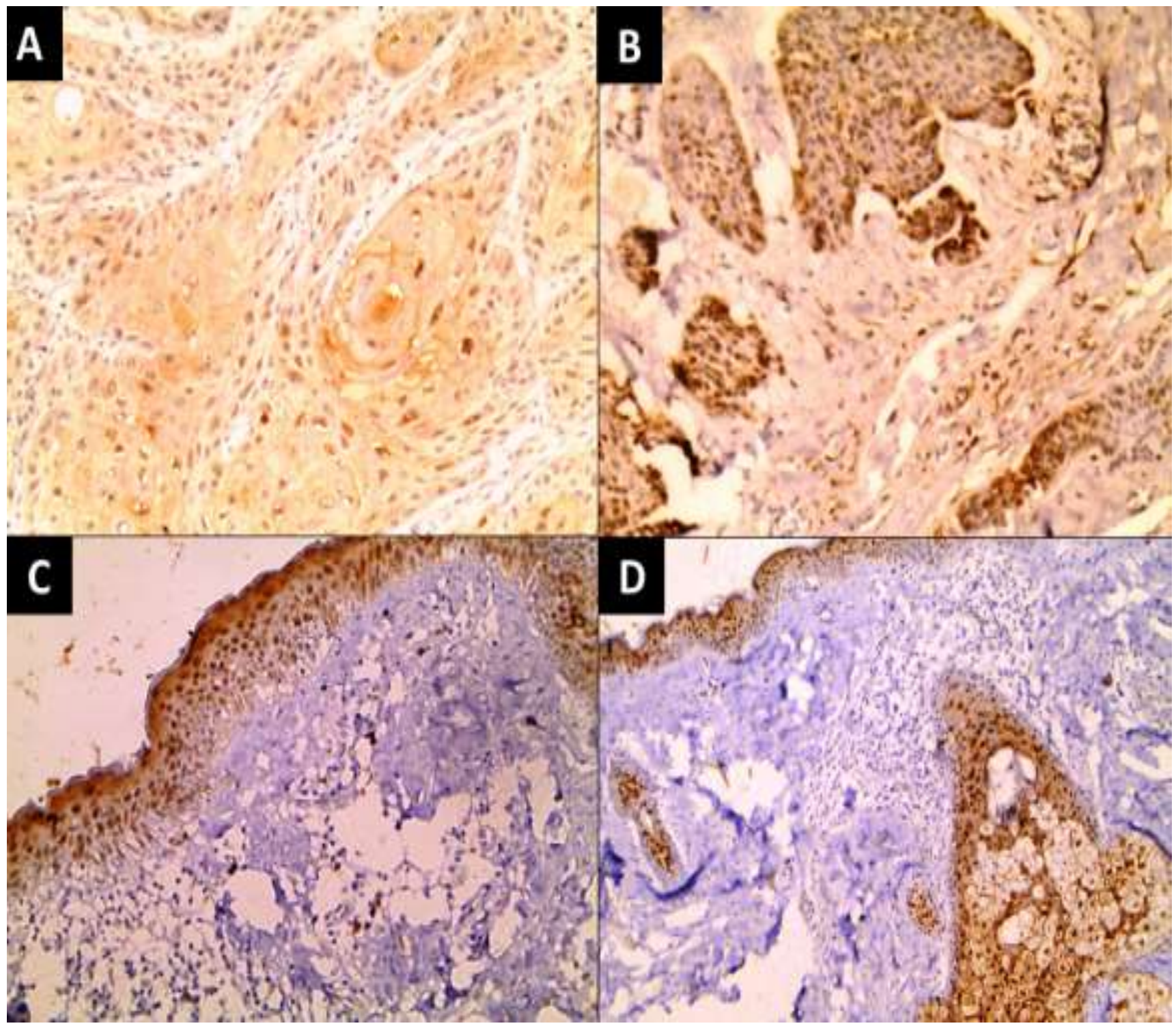

Figure (1): A: Expression of HOXA9 in SCC with mild intensity and nucleocytoplasmic localization. B: Expression of HOXA9 BCC cases with mild intensity and nucleocytoplasmic localization. C: Expression of HOXA9 in control section with strong intensity, all layers distribution and nucleocytoplasmic localization. D: Expression of HOXA9 in skin adnexa with strong intensity and nucleocytoplasmic localization.

\section{Comparison between the studied groups regarding HOXA9 expression:}

There was significant higher HOXA9 H- score in control skin than NMSC ( $\mathrm{p}<0.001)$. In addition, when comparing control to SCC cases, there was significant positive HOXA9 expression $(\mathrm{p}<0.001)$, strong intensity $(\mathrm{P}$ $<0.001)$, diffuse pattern $(\mathrm{P}=0.008)$, nucleo-cytoplasmic localization $(\mathrm{P}=0.064)$, higher range of $\mathrm{H}$ - score and higher $\mathrm{H}$ - score percentage in control sections. In contrast, BCC showed significant lower HOXA9 positive expression $(\mathrm{p}<0.001)$ and patchy pattern $(\mathrm{P}=0.003)$ when compared to control skin (Table 2).

When comparing SCC cases and BCC cases regarding HOXA9 expression, SCC showed significant higher HOXA9 positive expression ( $\mathrm{p}<0.001)$, mild intensity $(\mathrm{P}=0.524)$, diffuse pattern $(\mathrm{P}=0.484)$, nucleo-cytoplasmic localization $(\mathrm{P}=0.684)$, higher range of $\mathrm{H}$ - score $(\mathrm{P}=0.022)$, higher $\mathrm{H}$ - score percent $(\mathrm{P}=0.017)$ than $\mathrm{BCC}$ cases (Table 2). 
Table (2): Comparison between the studied groups regarding HOXA9 expression.

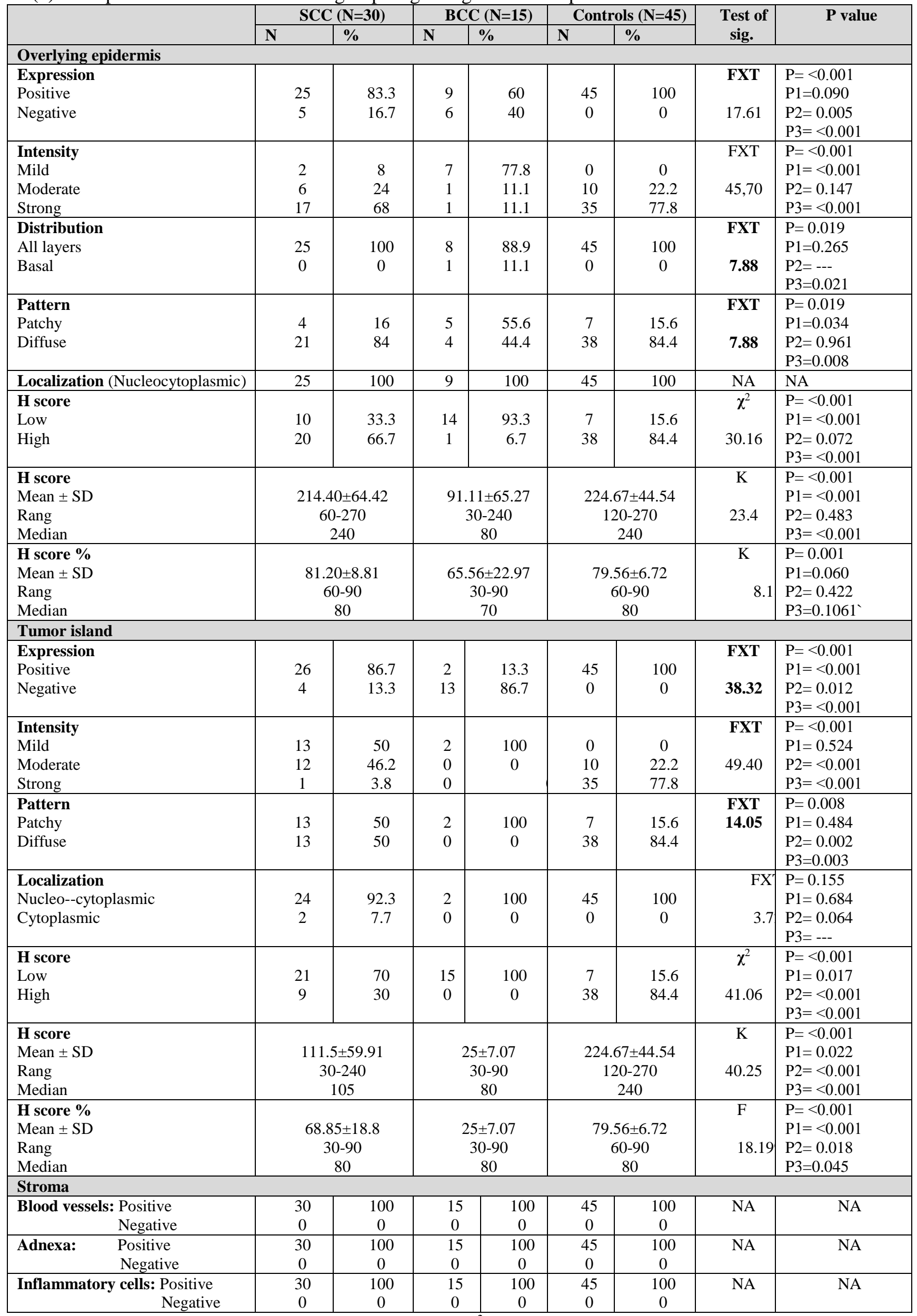

N: number X: Mean SD: standard deviation \%: percentage,$\chi^{2}$ :Chi-square test FXT: Fisher's exacts test K: Kruskal-Wallis test , P1: SCC vs BCC P2: SCC vs control P3: BCC vs control 
Correlation between HOXA9 expression and clinicopathological characteristics of studied SCC patients:

There was significant positive correlation between $\mathrm{H}$ score of HOXA9 in epidermis and size of lesion in $\mathrm{cm}(\mathrm{p}=0.015)$ (Figure 2).

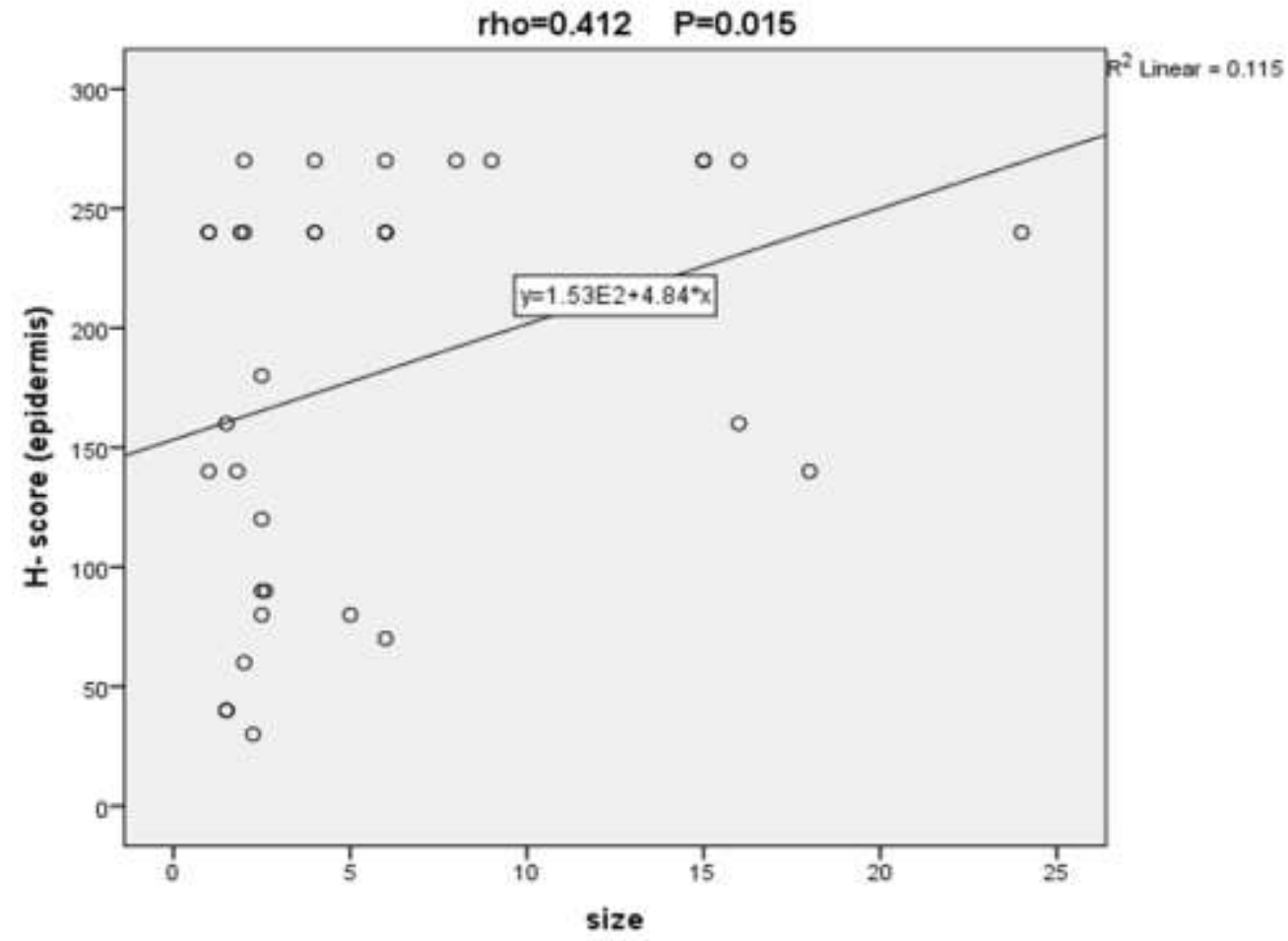

Figure 2: Correlation between HOXA9 expression in epidermis and size of lesion in $\mathrm{cm}$.

Relationship between HOXA9 H-score (epidermis) and clinicopathological data of studied SCC patients:

There was significant relationship between HOXA9 H score in epidermis and well differentiated $(\mathrm{p}=0.016)$ cases of SCC (Figure 3A).

Relationship between intensity of HOXA9 (tumor islands) and clinico pathological data of SCC Patients:

There was significant relationship between strong intensity of HOXA9 in tumor islands and well differentiated cases of SCC ( $\mathrm{p}=0.043)$ (Figure 3B).
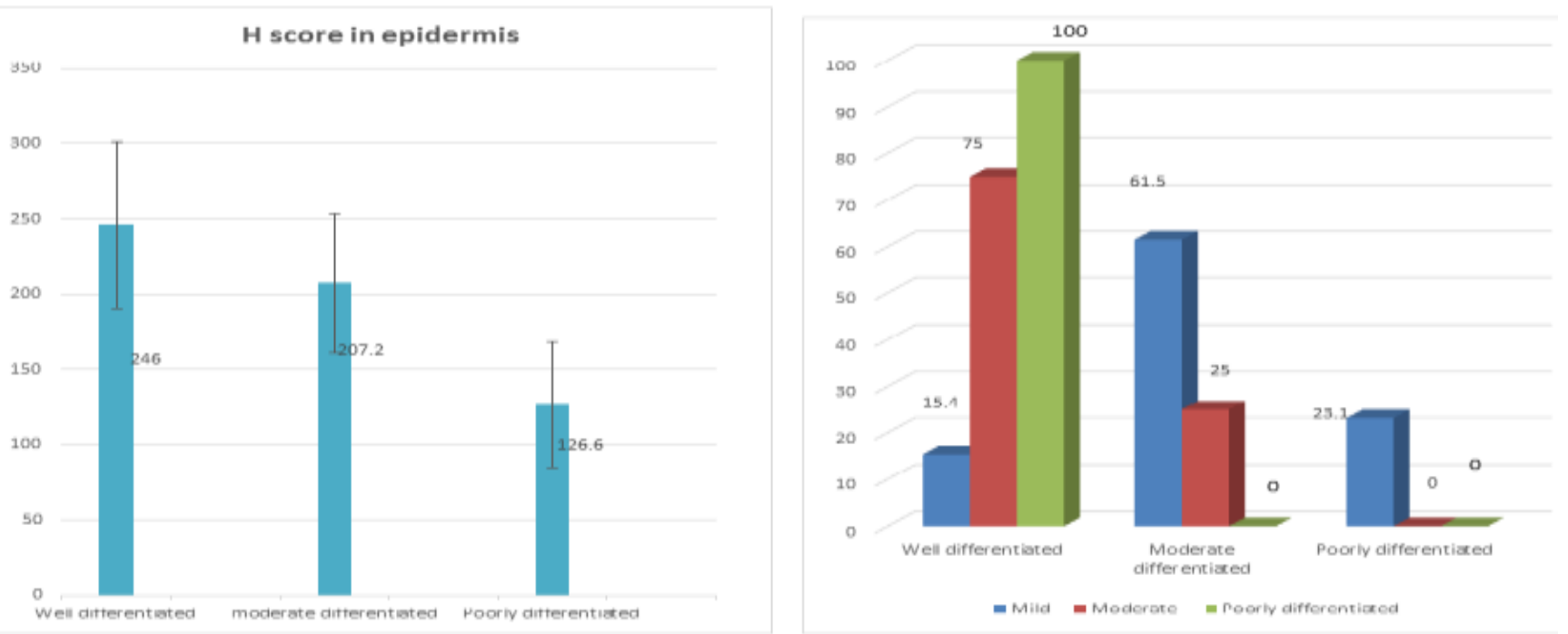

Figure (3): A: Relationship between HOXA9 H-score (epidermis) and well differentiated cases of SCC. B: Relationship between intensity of HOXA9 (tumor islands) and well differentiated cases of SCC.

Relationship between HOXA9 H- score (epidermis) and clinicopathological data of studied BCC patients:

There was significant relationship between HOXA9 H score in epidermis and involved margin of lesions of BCC patients $(\mathrm{p}=0.002)$ (Table 3). 
Table (3): Relationship between HOXA9 H- score (epidermis) and clinicopathological data of studied BCC patients.

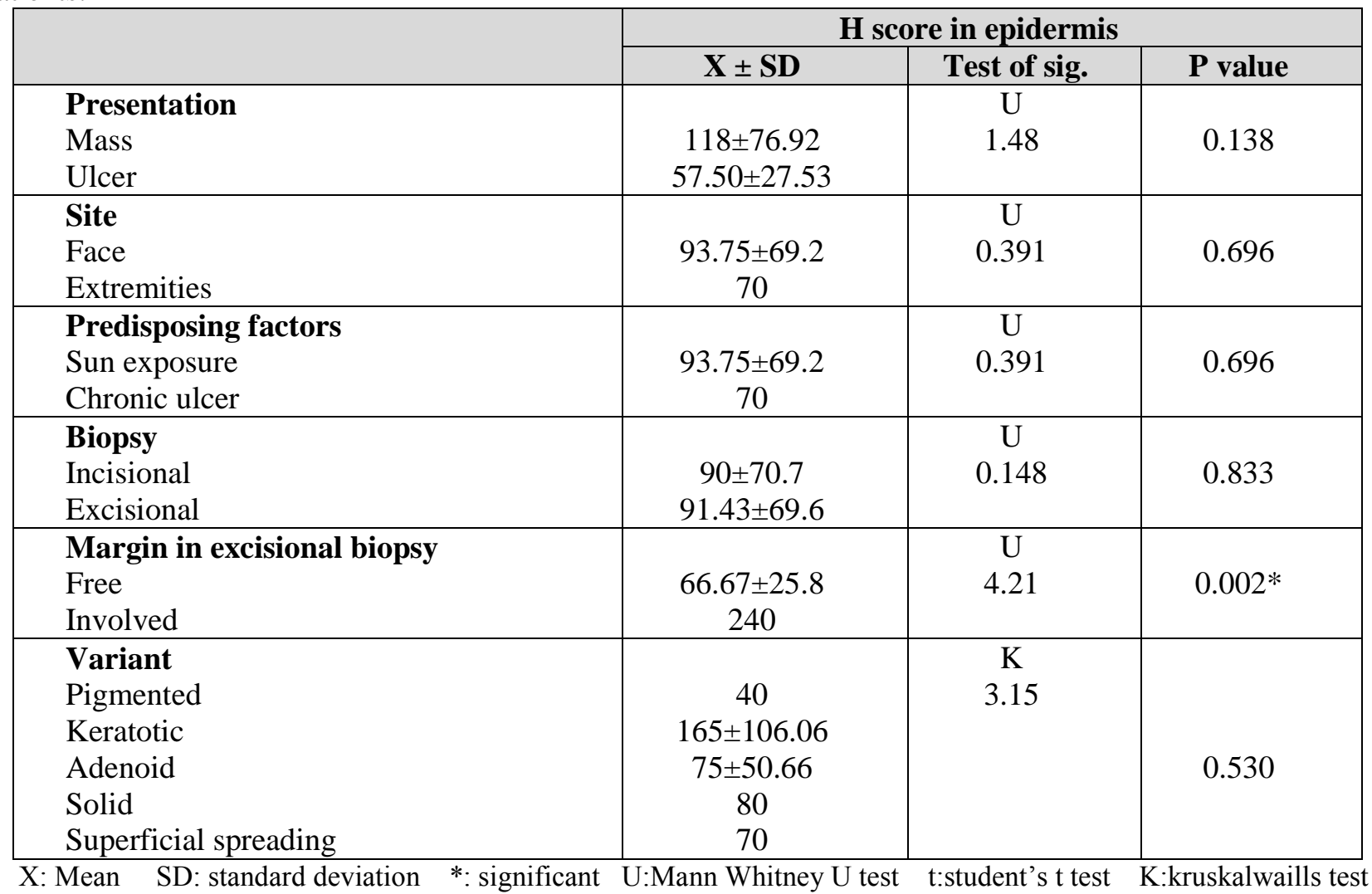

\section{DISCUSSION}

Skin malignancy is the most common group of malignant neoplasms in the white population and its incidence is increasing worldwide ${ }^{(\mathbf{1 4})}$. In comparison with melanoma which originates from melanocytes and is much more aggressive disease; NMSCs arise from skin keratinocytes and, in most cases, has a good prognosis and a better cure rate, principally due to the fact that it remains restricted to its primary site of the tumor ${ }^{(15)}$.

Homeobox (HOX) genes encode homeoproteins; a family of homeodomain-containing transcription agents. In mammalian cells, the HOX family consists of 39 transcription factors that play chief roles in embryonic development ${ }^{(\mathbf{1 6})}$.

Besides, emerging information points to that the function of HOX genes as oncogene by stimulating cellular growth and invasion or as tumor suppressors as they can modify survival of cell survival cell morphogenesis ${ }^{(\mathbf{1 7})}$.

This study was aimed to study role of HOXA9 in NMSC by immunohistochemical study and to correlate its expression with the available clinicopathological data.

In this study HOXA9 localization was nucleocytoplasmic in all sections of control skin and in all positive cases of SCC and BCC. Ma et al. ${ }^{(18)}$, mentioned in his study that immuno-histochemical staining of gastric carcinoma showed that positive HOXA9 staining was mainly located in the cytoplasm and the nucleus. Also, Gilbert et al. ${ }^{(\mathbf{1 9})}$, stated that the epithelium of the normal breast co- expressed obvious levels of both nuclear and cytoplasmic HOXA9.

Watanabe et al. ${ }^{(8)}$, reported that expression of HOXA9 was identified in the nucleus of the colorectal cells and the rate of HOXA9 positive expression was significantly related to higher tumor invasion and positive metastasis to lymph node.

In the current study, control skin showed statistically significant positive expression of HOXA9 higher $\mathrm{H}$ score value when compared to cases with SCC and BCC.

This result was in line with Zhou et al. ${ }^{(20)}$, who documented that HOXA9 is downregulated in CSCC cells and primary CSCC tumors and clarified that HOXA9 is acting by inhibition of cellular proliferation, migration, and invasiveness in CSCC, and stimulating cell apoptosis and also documented downregulation of HOXA9 by micro RNA365 (miR365) overexpression and that HOXA9 may have an anti-carcinogenic role in CSCC tumorigenesis.

Supporting our results, HOX-A9 was found to be silenced epigenetically in cutaneous malignant melanoma ${ }^{(21)}$. As aberrant DNA methylation has an important role in formation of tumor and progression. Hypermethylation of tumor suppressor genes leads to decreased expression of gene thus contributing to the pathogenesis of melanoma ${ }^{(22)}$. Indeed, Gilbert $\boldsymbol{e t} \boldsymbol{a l}$. (19), found a reduced levels of HOXA9 in breast tumors which was associated with increased breast tumor aggression, enhanced cancer metastasis, and a poor clinical prognosis. HOXA9 inhibits progression of 
breast cancer by regulating the expression of the tumor suppressor gene; BRCA1 which is commonly lost in sporadic human breast tumors, even in the absence of genetic modification ${ }^{(23)}$.

On the contrary; Sun et al. ${ }^{(24)}$, found that HOXA9 was upregulated in head and neck SCC (HNSCC) by analyzing messenger RNA (mRNA) level of HOXA9 and western blotting and stated that knockdown of HOXA9 results in inhibited cellular proliferation, migration, invasion, and chemoresistance but encouraged apoptosis. This may be due to different technique used in this study.

Han et al. ${ }^{(25)}$, explained loss of HOXA9 in CSCC. They reported that HOXA9 promote apoptosis in cutaneous squamous cell carcinoma and represses autophagy by affecting the pathway of nuclear factor kappa-light-chain-enhancer of activated B cells

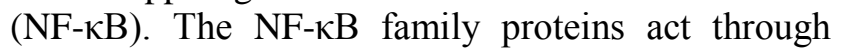
activation of cell proliferation, cell migration and invasion and inhibition of apoptosis ${ }^{(26)}$. The NF- $\kappa B$ in humans is transcriptionally repressed by HOXA9 and thus loss of HOXA9 in CSCC significantly enhances $\mathrm{NF}-\kappa \mathrm{B}$ pathway and may represent an intervention target therapy for $\operatorname{CSCC}^{(25)}$.

With the increase in volume, tumors will continually suffer from hypoxia owing to their ineffective poor vascular supply. Tumor cells subsequently are required to meet their oxygen demand by altering their metabolic rate, such as glycolytic reconstructing from oxidative phosphorylation (OXPHOS) to glycolysis ${ }^{(27)}$.

The pathway of hypoxia inducible factor (HIF)1 is mainly tangled in biological processes related to cancer including response to hypoxic, angiogenesis, cell cycle and glycolysis ${ }^{(28)}$. The accumulation of HIF-1 $\alpha$ will significantly reduce the efficiency of OXPHOS and encourages glycolysis to enhance cellular survival under both hypoxic and normoxic situations ${ }^{(29)}$. It was found that loss of HOXA9 will up regulate HIF-1 $\alpha$, which helps to regulate response to hypoxia, metabolism of glucose and tumor progression ${ }^{(30)}$.

In this study there was significant relationship between intensity of HOXA9 in tumor islands and histopathological grade of SCC cases that was higher in well differentiated cases and tend to decrease in moderate and poorly differentiated cases $(\mathrm{p}=0.043)$.

This matches the study of Zhou et al. ${ }^{(20)}$, who mentioned that, the score of HOXA9 staining was inversely correlated with ascending grades of CSCC. Precisely, an evident decreasing trend was detected across normal tissue.

In this study HOXA9 showed positive expression in all studied groups regarding blood vessels and adnexa. This was in line with Bhatlekar et al. (31), who reported that HOX genes are transcription factors that control the expression of multiple genes influencing cellular growth and viability and that mediate the interaction of stromalepithelial tissue to drive tissue-specific differentiation.

These results also matched with the study done by Bruhl et al. ${ }^{(32)}$, Nova-Lampeti et al. ${ }^{(33)}$, who reported that HOXA9 regulates angiogenesis and stimulate endothelial cell migration and documented that HOXA9 has a precise role in migration of endothelial cells without affecting other processes such as cell cycle/division.

In our study, HOXA9 was positive in $2(13.3 \%)$ of BCC cases with mild intensity and patchy nucleocytoplasmic pattern. BCC showed significant lower HOXA9 positive expression $(\mathrm{p}<0.001)$ and patchy pattern $(\mathrm{P}=0.003)$ when compared to control skin. Therefore HOXA9 showed reduced expression in BCC and may be involved in its pathogenesis. To our knowledge no studies have discussed the effect of HOXA9 on BCC until now and this is the first study discussing the immunohistochemical expression of HOXA9 in BCC.

It was found that HOXA9 expression was mainly located in the basal layer of the epidermis in both hypertrophic scar tissues and in the normal skin tissues, while rarely expressed in the dermis. It was also established that HOXA9 is involved in the transcriptional up-regulation of the vascular endothelial growth factor gene in epidermal stem cells in addition to its multi-differentiation potential and highly proliferative properties ${ }^{(34)}$ and this may explain its mild expression in BCC.

\section{CONCLUSION}

It could be concluded that HOXA9 in NMSC has an anticarcinogenic role in NMSC tumorigenesis that may provide novel intervention targets for NMSC therapy.

\section{REFERENCES}

1. Cives M, Mannavola $F$, Lospalluti $L$ et al. (2020): Non-Melanoma Skin Cancers: Biological and Clinical Features. Int J Mol Sci., 21 (15):5394-99.

2. Nikolouzakis T, Falzone L, Lasithiotakis $\mathrm{K}$ et al. (2020): Current and Future Trends in Molecular Biomarkers for Diagnostic, Prognostic, and Predictive Purposes in Non-Melanoma Skin Cancer. J Clin Med., 9(9):2868-75.

3. Samarasinghe $\mathbf{V}$, Madan $\mathbf{V}$ (2012): Nonmelanoma skin cancer. J Cutan Aesthet Surg., 5 (1):3-10.

4. Bray F, Ferlay J, Soerjomataram I et al. (2018): GLOBOCAN estimates of incidence and mortality worldwide for 36 cancers in 185 countries. CA Cancer J Clin., 68(6):394-424.

5. Silverberg M, Leyden W, Warton E et al. (2013): HIV infection status, immunodeficiency, and the incidence of non-melanoma skin cancer. J Natl Cancer Inst., 105(5):350-60. 
6. Mark M, Rijli F, Chambon P (1997): Homeobox genes in embryogenesis and pathogenesis. Pediatr Res., 42(4):421-9.

7. Collins C, Hess J (2016): Deregulation of the HOXA9/MEIS1 axis in acute leukemia. Curr Opin Hematol., 23(4):354-61.

8. Watanabe Y, Saito M, Saito $\mathrm{K}$ et al. (2018): Upregulated HOXA9 expression is associated with lymph node metastasis in colorectal cancer. Oncol Lett., 15(3):2756-2762.

9. Broders A (1921): Squamous cell epithelioma of the skin. Ann Surg., 20:141- 160.

10. Shehata W, Maraee A, Abdo E et al. (2021): Role of CYR61 in psoriatic lesional and perilesional skin: A clinical and immunohistochemical study. J Cosmet Dermatol., 2021: 1-8.

11. Oh S, Yang K, Kim Y et al. (2018): Increased immunoreactivity for TRPM8 in cutaneous squamous cell carcinoma. J Cutan Pathol., 45 (12):970-972.

12. Hemida A, Mareae A, Elbasiony A et al. (2020): Plexin-B2 in psoriasis, a clinical and immunohistochemical study. J Immunoassay Immunochem., 41(4):718-728.

13. Di Leo G, Sardanelli F (2020): Statistical significance: $p$ value, 0.05 threshold, and applications to radiomics-reasons for a conservative approach. Eur Radiol Exp., 4: 18.

14. Migden $M$, Rischin D, Schmults C et al. (2018): PD1 Blockade with Cemiplimab in Advanced Cutaneous Squamous-Cell Carcinoma. N Engl J Med., 379(4):341-351.

15. Marzuka A, Huang $L$, Theodosakis $N$ et al. (2015): Melanoma Treatments: Advances and Mechanisms. J Cell Physiol., 230(11):2626-33.

16. Luo Z, Rhie S, Farnham $P$ (2019): The Enigmatic HOX Genes: Can We Crack Their Code? Cancers (Basel), 11(3):323-27.

17. Gonçalves C, Le Boiteux E, Arnaud P et al. (2020): HOX gene cluster (de)regulation in brain: from neurodevelopment to malignant glial tumours. Cell Mol Life Sci., 77 (19):3797-3821.

18. Ma Y, Zhang Y, Mou X et al. (2017): High level of homeobox A9 and PBX homeobox 3 expression in gastric cancer correlates with poor prognosis. Oncol Lett., 14(5):5883-5889.

19. Gilbert $\mathbf{P}$, Mouw J, Unger $M$ et al. (2010): HOXA9 regulates BRCA1 expression to modulate human breast tumor phenotype. J Clin Invest., 120(5):153550.

20. Zhou L, Wang Y, Zhou M et al. (2018): HOXA9 inhibits HIF-1 $\alpha$-mediated glycolysis through interacting with CRIP2 to repress cutaneous squamous cell carcinoma development. Nat Commun., 9(1):1480-86.

21. Furuta J, Nobeyama Y, Umebayashi Y et al. (2006): Silencing of Peroxiredoxin 2 and aberrant methylation of $33 \mathrm{CpG}$ islands in putative promoter regions in human malignant melanomas. Cancer Res., 66(12):6080-6.

22. Gao L, Smit M, van den Oord J et al. (2013): Genome-wide promoter methylation analysis identifies epigenetic silencing of MAPK13 in primary cutaneous melanoma. Pigment Cell Melanoma Res., 26(4):54254.

23. Reynolds P, Sigaroudinia M, Zardo G et al. (2006): Tumor suppressor p16INK4A regulates polycombmediated DNA hypermethylation in human mammary epithelial cells. J Biol Chem., 281(34):24790-24802.

24. Sun Q, Zhang S, Zhao J et al. (2020): HIF-1 $\alpha$ or HOTTIP/CTCF Promotes Head and Neck Squamous Cell Carcinoma Progression and Drug Resistance by Targeting HOXA9. Mol Ther Nucleic Acids, 20:164175.

25. Han S, Li X, Liang $X$ et al. (2019): HOXA9 Transcriptionally Promotes Apoptosis and Represses Autophagy by Targeting NF- $\kappa \mathrm{B}$ in Cutaneous Squamous Cell Carcinoma. Cells, 8 (11):1360-66.

26. Taniguchi K, Karin M (2018): NF- $\kappa B$, inflammation, immunity and cancer: coming of age. Nat Rev Immunol., 18(5):309-324.

27. Ward P, Thompson C (2012): Metabolic reprogramming: a cancer hallmark even warburg did not anticipate. Cancer Cell, 21(3):297-308.

28. Cavadas M, Mesnieres M, Crifo B et al. (2015): REST mediates resolution of HIF-dependent gene expression in prolonged hypoxia. Sci Rep., 5:1785158.

29. Zhao T, Zhu Y, Morinibu A et al. (2014): HIF-1mediated metabolic reprogramming reduces ROS levels and facilitates the metastatic colonization of cancers in lungs. Sci Rep., 4:3793-98.

30. García-Sancha N, Corchado-Cobos R, PérezLosada J et al. (2019): MicroRNA Dysregulation in Cutaneous Squamous Cell Carcinoma. Int J Mol Sci., 20(9):2181-86.

31. Bhatlekar S, Fields J, Boman B (2018): Role of HOX Genes in Stem Cell Differentiation and Cancer. Stem Cells Int., 2018:3569493.

32. Bruhl T, Urbich C, Aicher D et al. (2004): Homeobox A9 transcriptionally regulates the EphB4 receptor to modulate endothelial cell migration and tube formation. Circ Res., 94 (6):743-751.

33. Nova-Lampeti E, Aguilera $\mathrm{V}$, Oporto $\mathrm{K}$ et al. (2018): Hox genes in adult tissues and their role in endothelial cell differentiation and angiogenesis." Endothelial Dysfunction - Old Concepts and New Challenges, Helena Lenasi, DOI: 10.5772/ intechopen.76745.

34. Cao P, Xu Y, Tang J et al. (2014): HOXA9 regulates angiogenesis in human hypertrophic scars: induction of VEGF secretion by epidermal stem cells. Int J Clin Exp Pathol., 7(6):2998-3007. 